\title{
THE SIGNIFICANCE OF CHANGES IN THE ELECTROCARDIOGRAM IN HYPOTHERMIA
}

\author{
BY \\ D. EMSLIE-SMITH, ${ }^{*}$ G. E. SLADDEN, $\uparrow$ AND G. R. STIRLING $\ddagger$
}

From the Baker Medical Research Institute and Alfred Hospital Clinical Research Unit, Melbourne, Australia

Received June 4, 1958

Death from ventricular fibrillation is the gravest risk that attends the current use of hypothermia in surgery of the heart and brain. Any reliable warning of its approach would clearly be important.

In 1938 Tomaszewski published electrocardiograms from an accidentally frozen patient that showed an extra, slowly inscribed deflection between the QRS complex and the early part of the S-T segment. This deflection was produced experimentally in dogs in 1943 by Grosse-Brockhoff and Schoedel, and has been described by several workers since, both in patients and in animals deliberately cooled. Osborn (1953) considered that it represented a current of injury caused by the acidosis that develops in hypothermic animals allowed to breathe spontaneously: he thought that it heralded ventricular fibrillation and was a very bad prognostic sign. This opinion has been repeatedly quoted and very recently Fleming and Muir (1957) considered that the association of the deflection with ventricular fibrillation was confirmed. This view received theoretical backing from the work of Hegnauer and his colleagues (Covino and Williams, 1955; Covino and Hegnauer, 1955). They thought that during the time occupied by the deflection, the threshold of cardiac muscle to artificial stimulation was strikingly reduced. Hegnauer has, however, recently stated that these conclusions were invalid, since the experiments were carried out by a technique that gave rise to artefacts unrecognized at the time (Hegnauer and Covino, 1956).

Although there is a danger that this cardiographic sign may be regarded as a warning of the onset of ventricular fibrillation, there have been few reports of the effect of deliberate hypothermia on the cardiogram of patients without heart disease (Lougheed et al., 1955; Gunton et al., 1956; Villamil et al., 1955, 1957; Emslie-Smith, 1956). Further, in the published accounts of the effects of hypothermia on the human cardiogram most workers seem to have followed changes in a single lead only, and the reported incidence of the characteristic deflection is very variable. The changes described in the S-T segment of the hypothermic dog are also varied and confusing.

In order to assess the significance of this deflection more carefully it has been studied in hypothermic patients with normal hearts, and by the use of direct epicardial electrodes in hypothermic dogs.

\section{MeTHODS}

Hypothermia in Human Subjects. Five anæsthetized patients, four of whom had no heart disease, were cooled by ice bags laid on the skin in preparation for craniotomy to arrest subarachnoid hæmorrhage. There were 4 women and 1 man, aged 35 to 49 years. While the temperature fell the multiple-lead cardiogram was continuously monitored in a cathode ray oscilloscope, and recorded when any change was seen. The technical details were described in a previous paper (Emslie-Smith, 1956) and the further subjects of

* Edward Wilson Memorial Fellow, 1955-56. Present address: Dept. of Medicine, Postgraduate Medical School of London, Hammersmith, W.12.

$\dagger$ Late of the Dept. of Anæsthesia, Alfred Hospital.

$\ddagger$ Sidney Jones Fellow, 1956 . 
the present report bring the number of the total series to ten patients, eight of whom were without heart disease.

Hypothermia in the Dog. Hypothermia, in preparation for experimental surgery, was produced by skin cooling 55 times in 47 anæsthetized dogs. Electrocardiograph tracings were recorded during cooling, but before any cardiac surgery was begun, on a direct-writing cardiograph (Electrite, Cambridge Instrument Co.) from unipolar surface leads, and from csophageal, direct epicardial, and intracavitary leads. Anæsthesia was induced by intravenous pentobarbitone and maintained by nitrous oxide and oxygen. Respiration was controlled by hand or by an automatic respirator (Vivrator, Aga, Stockholm). Esophageal temperatures were read from a mercury thermometer or recorded from a thermistor.

In 34 experiments moment-to-moment changes in lead aVF were noted by watching the oscilloscope during the whole of cooling. Unipolar præcordial leads were recorded in 22 cases. In 17 experiments the thorax was opened and direct electrograms were recorded from the exposed epicardium of the ventricles, using as exploring electrode a soft saline-moistened wick attached to the unipolar exploring lead of the electrocardiograph. In 3 of these experiments changes in the epicardial electrogram were followed during the whole of the cooling procedure. In 4 experiments electrodes recorded the potentials in the cavities of the right and left ventricles.

The $\mathrm{pH}$ of arterial blood was continuously measured in 9 dogs by shunting blood from the femoral artery to the femoral vein through a glass electrode system. In some experiments allowance for the temperature coefficient of the glass electrode cell, based on the œsophageal temperature, was made in the calculation; in others the potentiometer was automatically compensated by means of a thermistor inserted in the electrode system.

\section{RESULTS}

Hypothermia in Human Subjects. The results in 5 further patients here reported are similar to those from 5 others described in a previous paper (Emslie-Smith, 1956) but included in the tables. In all cases the heart rate slowed with falling temperature, and the PR and QTc intervals increased.

The characteristic slowly-inscribed deflection appeared in the early part of the S-T segment in some leads from all patients, though differing in degree and in the temperature at which it appeared. It was directed upward in leads related to the left ventricle. Although obvious in left præcordial leads, it was sometimes not apparent in limb leads or was represented there merely by a widening of the base of the QRS complex. It grew in amplitude as the temperature fell and in one case it exceeded the $R$ wave in lead V3. When it became very high the $\mathrm{T}$ wave became inverted. As in the series previously reported, it was most conspicuous in the thinnest patient (Case 4). In all cases the changes were reversible on warming.

A detailed description of the changes in the electrocardiogram in three representative cases follows.

Severe Changes. Case 4 (Fig. 1). Before cooling. Normal sinus rhythm. The electrocardiogram was normal and showed a vertical heart position. During cooling. The intervals RR, PR, "QS" (see Table I), QT and QTc lengthened. At $35.2^{\circ} \mathrm{C}$. the slow deflection early in S-T appeared and subsequently increased in size. It was directed upward in leads I, II, III, aVF, and V3R to V5, downward in aVR and aVL. T became diphasic in leads I, II, III, aVL, and V5, and reversed in V1-V4 (downward). At $31^{\circ} \mathrm{C}$. the slow upward deflection in $\mathrm{V} 3 \mathrm{had}$ an amplitude of $2 \cdot 13 \mathrm{mV}$ and was actually higher than $\mathrm{R}$. This patient was by far the thinnest person in the series, and his cardiogram showed the severest changes, although atrial fibrillation did not develop.

Moderate Changes. Case 3 (Fig. 2). Before cooling. Normal sinus rhythm. The heart was in the intermediate position with slight anticlockwise rotation. The tracing was normal. During cooling. The intervals RR, PR, “QS," QT, and QTc lengthened. At $36.25^{\circ} \mathrm{C}$. fairly frequent ventricular ectopic beats appeared, but become fewer, and eventually disappeared as the temperature fell. At $35.3^{\circ} \mathrm{C}$. the slow deflection in early S-T appeared, and subsequently increased in size. It was directed upward in leads I, aVL, and V4, and downward in aVR. There was widening and ledging of the base of QRS in leads II, III, aVF, and V1. Atrial fibrillation occurred at $35.3^{\circ} \mathrm{C}$. The appearance of frequent ectopic beats was unusual, but the changes in the form of the complexes were of the degree most commonly seen.

Mild Changes. Case 2 (Fig. 3). Before cooling. Normal sinus rhythm. The heart was vertical with slight clockwise rotation. The tracing was abnormal in that $\mathrm{T}$ was directed downward in V3 and was diphasic in V4. During cooling. The intervals RR, PR, "QS," QT, and QTc lengthened. At $32 \cdot 5^{\circ} \mathrm{C}$. the slow deflection in early $\mathrm{S}-\mathrm{T}$ appeared, and subsequently increased in size. It was directed upward in leads I, aVL, and V4, with widening of the base of QRS in leads II, III, aVR, aVF, and V1. Changes as mild as these were very unusual. They might have been overlooked if serial records were not compared. 


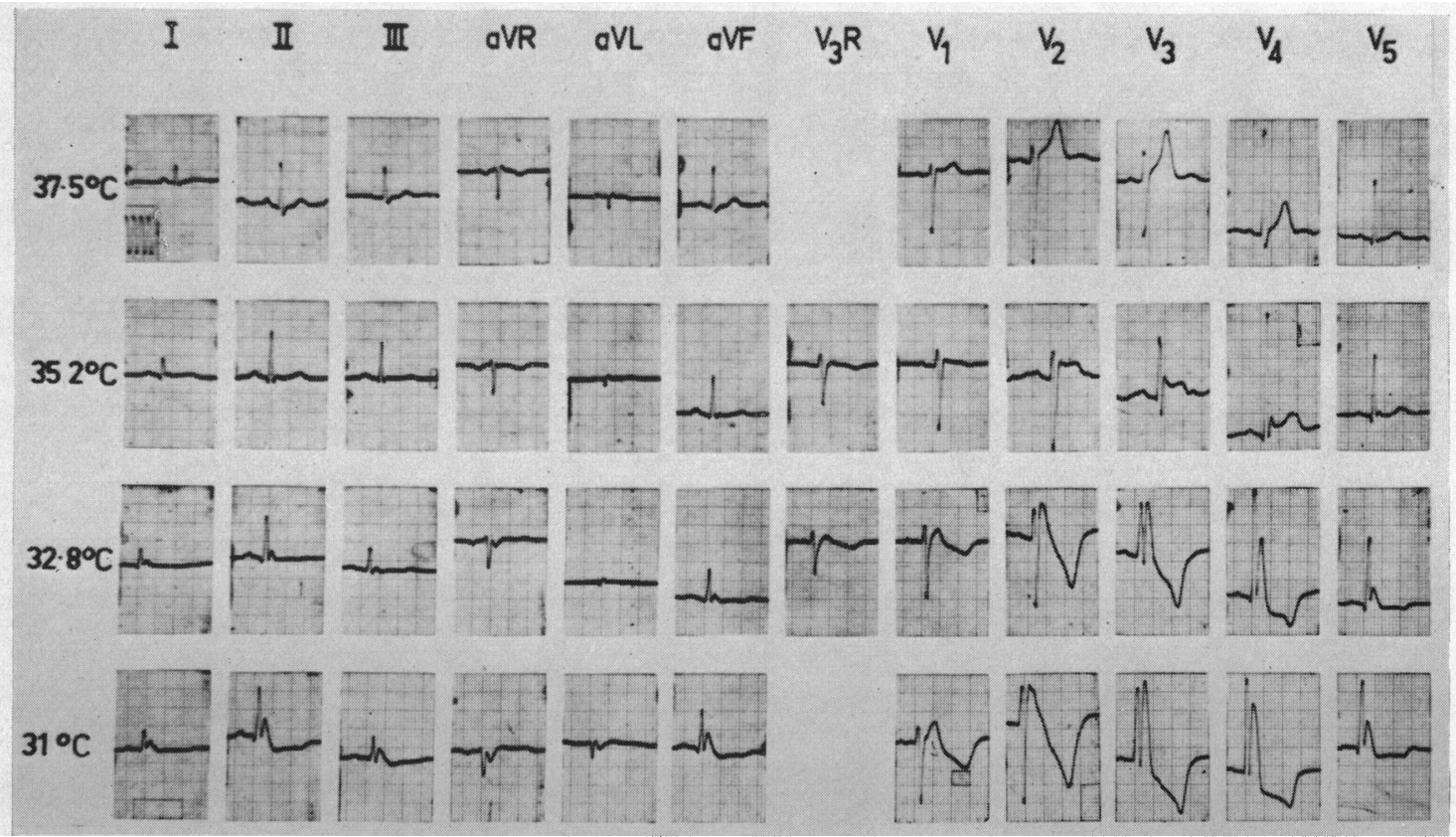

FIG. 1.-Case 4. Severe changes in the human electrocardiogram during cooling, showing at $31^{\circ} \mathrm{C}$. (rectal) conspicuous slow deflections in early S-T (J deflections) directed upward in leads I, II, III, aVF, and V3R to V5, downward in aVR, aVL. T becomes diphasic in leads I, II, III, aVL, V5, and reversed in V1 to V4. The deflection in $\mathrm{V} 3$ at $31^{\circ} \mathrm{C}$. has an amplitude of $2.13 \mathrm{mV}$, and is higher than $\mathrm{R}$. This patient was the thinnest of the series.

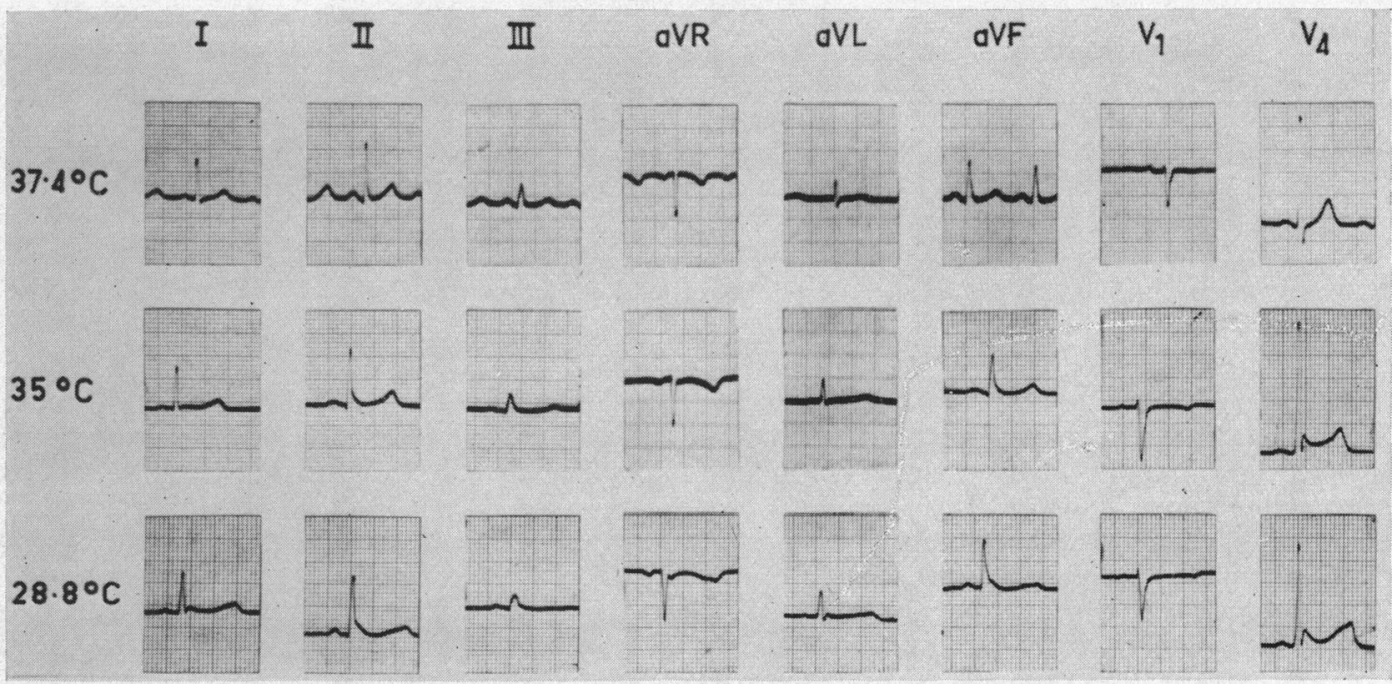

FIG. 2.-Case 3. Moderate changes in the human electrocardiogram during cooling, showing at $28 \cdot 8^{\circ} \mathrm{C}$. (rectal) the typical J deflection, directed upwards in leads I, aVL, V4, and downward in aVR, and the widening, with ledging, of the base of QRS in leads II, III, aVF, and V1. 
TABLE I

Measurements from Ei.ectrocardiograms of Ten Anasthetised Patients Before and After Cooling

\begin{tabular}{|c|c|c|c|c|c|}
\hline Case No. & $\begin{array}{c}\text { Rectal } \\
\text { temperature } \\
{ }^{\circ} \mathrm{C} .\end{array}$ & $\begin{array}{l}\text { Heart rate } \\
\text { (beats/min.) }\end{array}$ & $\begin{array}{l}\text { P-R } \\
(\mathrm{sec} .)\end{array}$ & $\begin{array}{l}\text { “QS”* } \\
\text { (sec.) }\end{array}$ & $\begin{array}{c}\text { QTc } \\
\text { (QT/VRR) } \\
\text { (sec.) }\end{array}$ \\
\hline \multirow[t]{2}{*}{ I } & "Normal" & 87 & $0 \cdot 12$ & 0.05 & 0.45 \\
\hline & 29 & 37 & 0.23 & 0.05 & 0.55 \\
\hline \multirow{2}{*}{ II } & $36 \cdot 5$ & 87 & $0 \cdot 16$ & 0.07 & 0.53 \\
\hline & 29 & 45 & 0.20 & 0.07 & 0.58 \\
\hline \multirow{2}{*}{ III } & $36 \cdot 5$ & 71 & 0.12 & 0.03 & 0.48 \\
\hline & $27 \cdot 2$ & 28 & $0 \cdot 18$ & 0.03 & 0.50 \\
\hline \multirow{2}{*}{ IV } & $36 \cdot 6$ & 105 & $0 \cdot 14$ & 0.05 & 0.48 \\
\hline & 29 & 60 & $0 \cdot 17$ & 0.05 & 0.54 \\
\hline \multirow{2}{*}{$\mathbf{V}$} & $36 \cdot 8$ & 104 & $0 \cdot 14$ & 0.04 & 0.49 \\
\hline & $28 \cdot 5$ & 40 & 0.21 & 0.04 & 0.60 \\
\hline \multirow{2}{*}{1} & 38 & 97 & $0 \cdot 16$ & 0.04 & 0.46 \\
\hline & $29 \cdot 3$ & 36 & $0 \cdot 16$ & 0.05 & 0.55 \\
\hline \multirow{2}{*}{2} & $37 \cdot 4$ & 88 & $0 \cdot 12$ & 0.05 & $0 \cdot 45$ \\
\hline & 28.8 & 45 & $0 \cdot 15$ & 0.06 & 0.55 \\
\hline \multirow{2}{*}{3} & $37 \cdot 5$ & 77 & $0 \cdot 16$ & 0.05 & 0.45 \\
\hline & 31 & 44 & 0.20 & 0.06 & 0.54 \\
\hline \multirow{2}{*}{4} & $37 \cdot 6$ & 79 & $0 \cdot 16$ & 0.05 & 0.46 \\
\hline & $31 \cdot 5$ & 34 & 0.23 & 0.07 & 0.54 \\
\hline \multirow{2}{*}{5} & $37 \cdot 2$ & 88 & $0 \cdot 14$ & 0.06 & 0.46 \\
\hline & $32 \cdot 8$ & 55 & 0.20 & 0.06 & 0.55 \\
\hline
\end{tabular}

* Measured from the onset of $Q$ to the end of the intrinsicoid deflection. Cases I-V belong to the previous series; Case 1-5 belong to the present series.

Table I shows the measurements of the various electrocardiographic intervals of all 10 patients. Table II shows the relation between temperature and the onset of both atrial fibrillation and the characteristic "hypothermia deflection" in all 10 patients. In both tables the patients I to V are those reported in detail in the previous paper.

Ventricular fibrillation did not occur. Neither in time of onset, nor in severity, did the changes in the cardiogram bear any relation to the onset of atrial fibrillation.

Hypothermia in the Dog. From the epicardial and cavity electrodes two basic patterns of changes in the S-T segment were recorded during cooling (Fig. 4). Over most of the epicardium of both ventricles the $\mathrm{T}$ wave was directed downward, and as cooling progressed there appeared early in the S-T segment a slowlyinscribed upward deflection which increased in amplitude and duration. This pattern was sometimes seen in surface leads (Fig. 5, Type 1) and was similar to the pattern recorded from left præcordial leads in the human subjects which showed the greatest changes. The second pattern resembled the first, but was opposite in sign, with the extra deflection directed downward, and an upwardly-directed $\mathrm{T}$ wave. This 


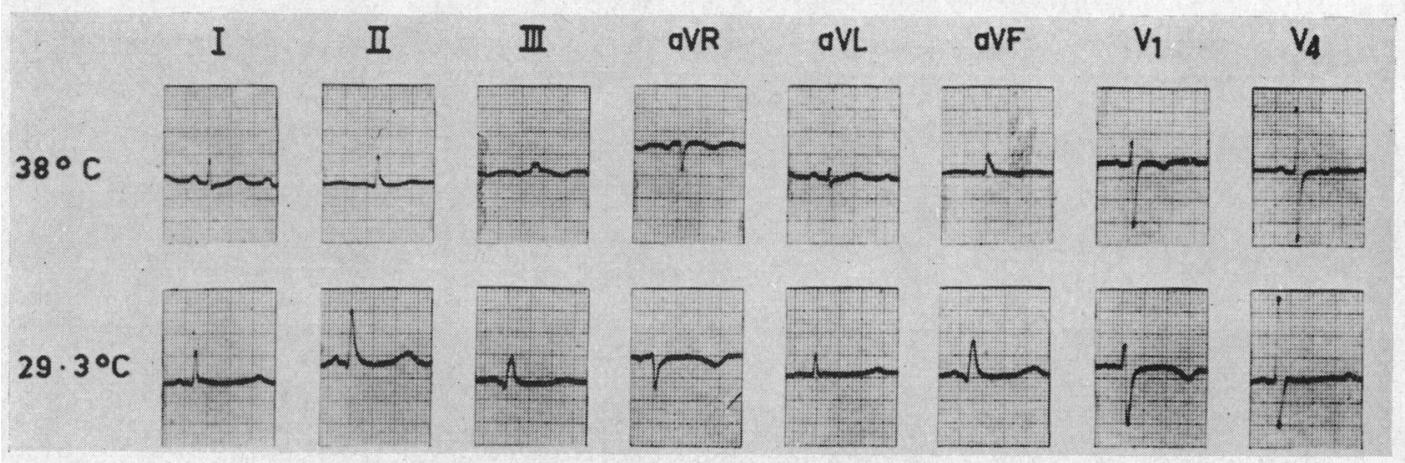

FIG. 3.-Case 2. Unusually mild changes in the human electrocardiogram during cooling. Small J. deflections are present at $29 \cdot 3^{\circ} \mathrm{C}$. in leads $\mathrm{I}, \mathrm{aVL}$, and $\mathrm{V} 4$, and there is widening of the base of $\mathrm{QRS}$ in leads II, III, aVR, aVF, and V1.

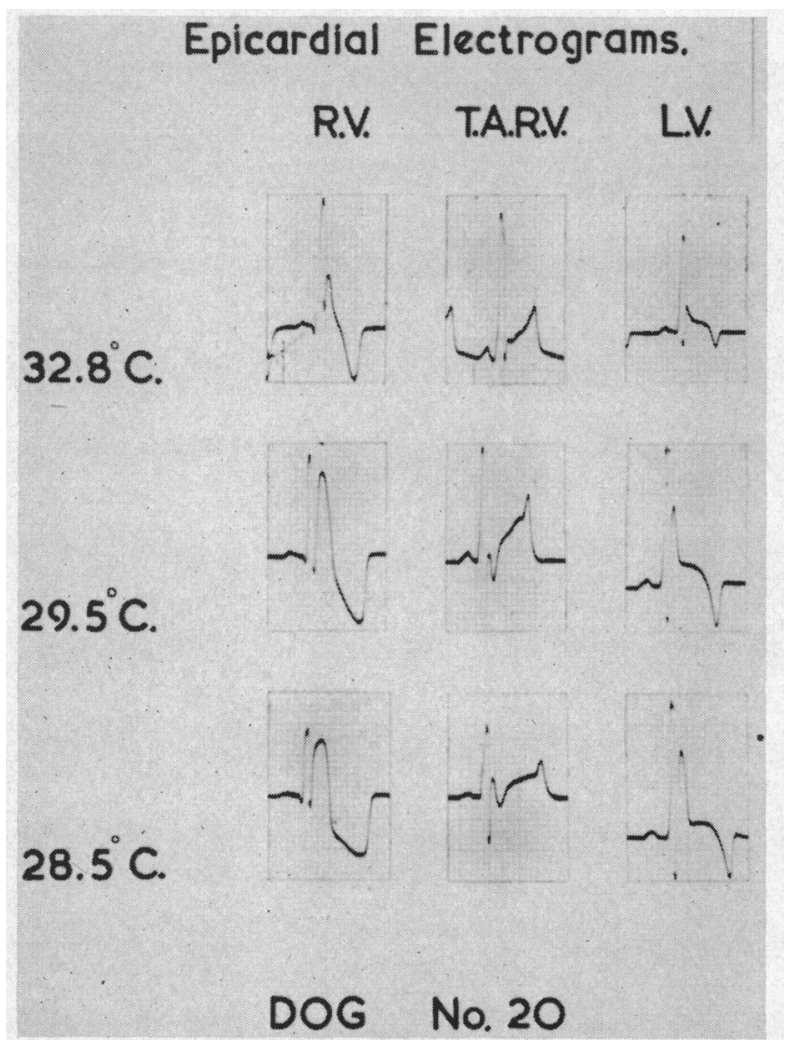

FIG. 4.-Epicardial electrograms recorded during the production of hypothermia in a dog. The pattern of ST-T segment recorded from the left ventricle (L.V.) and most of the right ventricle (R.V.) resembles that seen in left præcordial leads in Case 4 . The pattern recorded from the trabeculated area of the right ventricle (TARV) is similar, but of opposite sign, and resembles that recorded from the ventricular cavities and the atrial epicardium. 
TABLE II

Relation between Temperature and Onset of Atrial Fibrillation and Hypothermia Deflection in Man

\begin{tabular}{c|c|c}
\hline Case No. & $\begin{array}{c}\text { Temperature at which hypothermia } \\
\text { deflection first appeared } \\
\left({ }^{\circ} \mathrm{C} .\right)\end{array}$ & $\begin{array}{c}\text { Temperature at which atrial } \\
\text { fibrillation occurred } \\
\left({ }^{\circ} \mathrm{C} .\right)\end{array}$ \\
\hline I & $\begin{array}{c}\text { Small deflection present at normal } \\
\text { temperature }\end{array}$ & $27 \cdot 9$ \\
\hline II & $30 \cdot 3$ & - \\
\hline III & $32 \cdot 3$ & - \\
\hline IV & $35 \cdot 5$ & $28 \cdot 2$ \\
\hline V & $33 \cdot 2$ & $29 \cdot 5$ \\
\hline 1 & $32 \cdot 3$ & - \\
\hline 2 & $35 \cdot 3$ & 27.9 \\
\hline 3 & $35 \cdot 2$ & - \\
\hline 4 & $34 \cdot 6$ & $29 \cdot 0$ \\
\hline 5 & $35 \cdot 4$ & $31 \cdot 2$ \\
\hline
\end{tabular}

Mean temperature at which atrial fibrillation occurred: $28 \cdot 9^{\circ} \mathrm{C}$. (s.d. 1.17). Cases I-V belong to the previous series; Cases 1-5 belong to the present series.

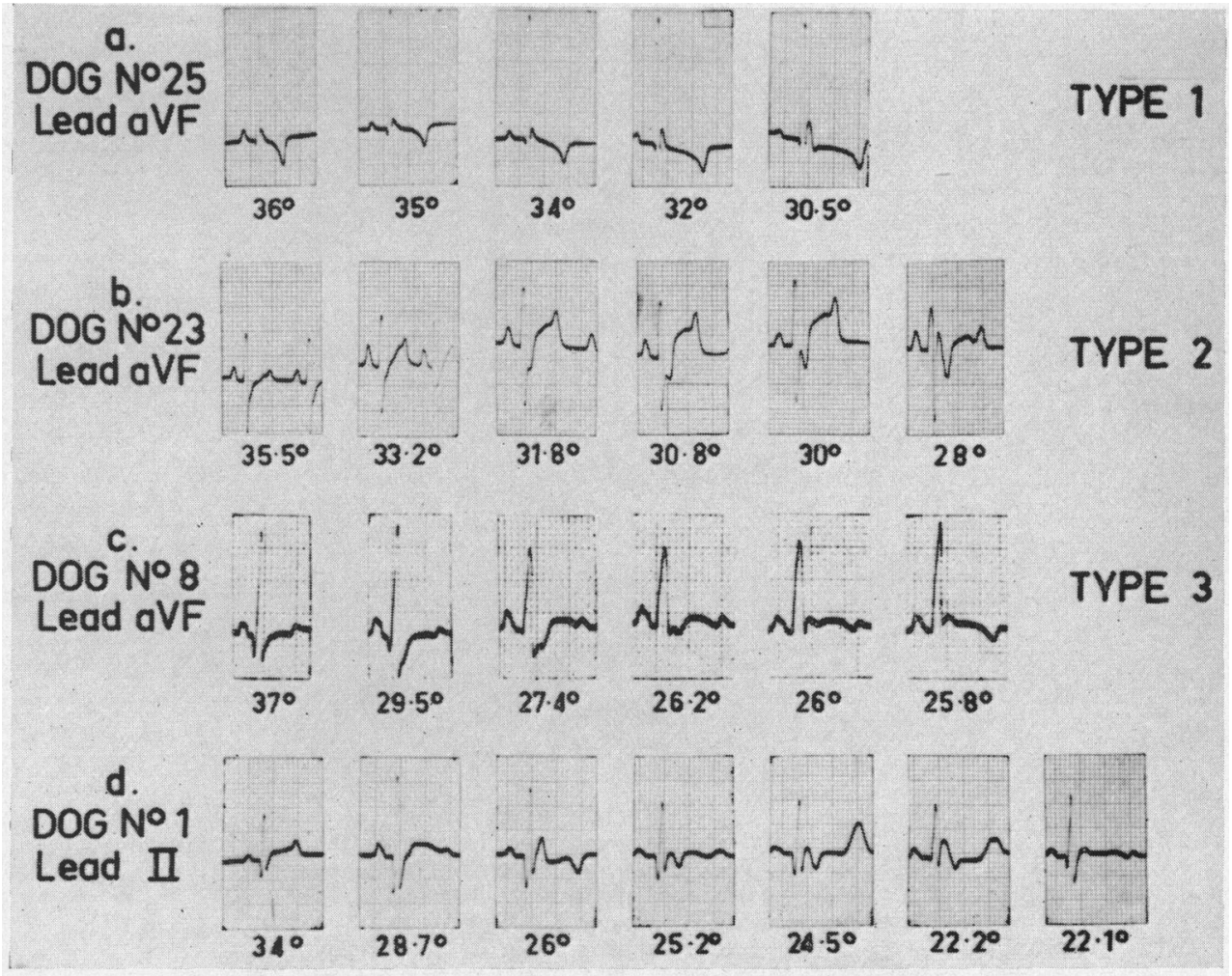

Fig. 5. - Serial tracings at falling temperatures $\left({ }^{\circ} \mathrm{C}\right.$.), showing three basic patterns seen in limb leads in hypothermic dogs. Types 1 and 2 resemble the two basic epicardial patterns (Fig. 4), Type 3 is a combination of Types 1 and 2 (Fig. 6). The series, " $d$ " shows a change from one basic type to another probably from alteration of the position of the heart during cooling. 
pattern was recorded from the cavities of both ventricles, from the epicardium of the atria and of the trabeculated area of the right ventricle, and from œsophageal and some surface leads (Fig. 5, Type 2).

Combinations of these two basic patterns were recorded by ordinary unipolar leads from boundary zones of the epicardium and from some surface leads (Fig. 5, Type 3). Similar combination patterns were reproduced by leading each of the two basic patterns simultaneously into the electrocardiograph by fork leads.

These changes always appeared in some leads at low temperatures. Consequently, when ventricular fibrillation occurred it did so after the appearance of these changes; but no correlation was found between the time of the onset or the severity of the changes and the onset of ventricular fibrillation. Further, in these experiments ventricular fibrillation was not constantly preceded by any particular arrhythmia, and usually sinus rhythm persisted until its sudden onset.

The study of the $\mathrm{pH}$ of arterial blood showed no correlation between the $\mathrm{pH}$ level and the presence of the "hypothermia deflection" (Fig. 6). At low temperatures the deflection was found to be well developed

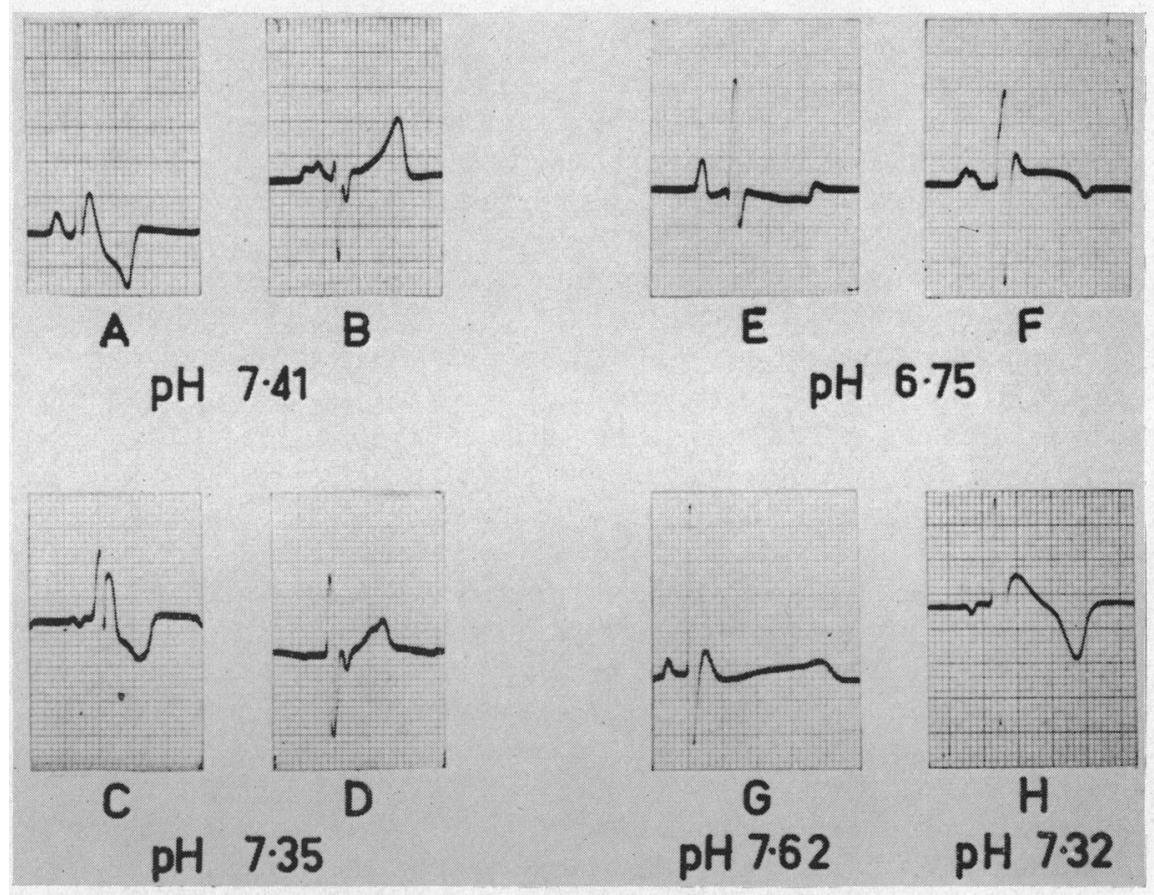

FIG. 6.-The characteristic deflection appeared in hypothermic dogs irrespective of blood pH. (A) and (B) Left chest leads from dog whose $\mathrm{pH}$ was kept normal during whole of cooling: (A) $26 \cdot 5^{\circ} \mathrm{C}$.; (B) $24.6^{\circ} \mathrm{C}$. Notice resemblance to (C) and (D). (C) and (D) Direct epicardial leads at $28 \cdot 5^{\circ} \mathrm{C}$. from dog whose $\mathrm{pH}$ was kept normal during cooling: (C) mid RV; (D) trabeculated area RV. Hypothermia deflection well developed. (E) and (F) Surface leads at $24 \cdot 5^{\circ} \mathrm{C}$. from an acidotic dog. ((E) aVF; (F) left chest). Hypothermia deflection absent from limb lead, obvious in chest lead. (G) and (H) Chest leads from $(\mathrm{G})$ dog at $22.5^{\circ} \mathrm{C}$. made progressively alkalotic by hyperventilation and from $(\mathrm{H}) \operatorname{dog}$ at $26^{\circ} \mathrm{C}$. in terminal acidosis (unassisted respiration).

in præcordial leads in dogs whose blood $\mathrm{pH}$ was kept normal throughout the whole procedure by varying their ventilation. It was also well developed in dogs with unassisted respiration before terminal acidosis began, and in dogs made alkalotic by hyperventilation. In one dog that was allowed to become progressively acidotic the deflection was present in præcordial leads but absent from tracings from lead aVF (Fig. 6E and F).

The onset of atrial fibrillation or nodal rhythm did not alter the typical deflection.

Three dogs of another series, which were given a similar anæsthetic without hypothermia for five hours, showed no changes in the S-T segment that resembled those produced by cooling. 


\section{DisCUSSION}

The characteristic deflection of hypothermia has sometimes been named after Osborn who discussed it in 1953; it was, however, clearly described by Grosse-Brockhoff ten years earlier (Grosse-Brockhoff and Schoedel, 1943). In the vectorcardiogram of hypothermic man and dog it is represented by an extra loop ("J loop") involving the junction (J) of the QRS and T loops (Emslie-Smith, 1958). It may therefore conveniently be termed the "J deflection". In this study of the multiple-lead cardiogram of hypothermic patients without heart disease the "J deflection" was invariably seen in some degree. Further, it was always found in some leads in the hypothermic dog. It is the first time that this uniformity has been reported. This is probably partly because patients with normal hearts were investigated and partly because multiple leads were employed in both the present studies, whereas other workers generally seem to have used a single lead, often lead II. This also explains the varied and confusing accounts that have previously been given of the canine cardiogram in hypothermia. It appears that in the dog the two basic epicardial patterns, or a combination of the two, are reflected by surface leads, possibly depending on the anatomical relationship of the surface lead to a given area of the epicardium. Since the position of the dog's heart within the thorax can alter considerably as its rate slows on cooling, this relationship varies, and a surface lead may reflect first one, then another, basic epicardial pattern as the temperature falls (Fig. 5d).

The similarity of the pattern obtained from most of the canine ventricular epicardium and that recorded from left præcordial leads in the human subjects whose cardiogram showed the most severe changes suggests that the changes in the dog are analogous to those in man.

The "J deflection" has been variously attributed to a conduction defect (Tomaszewski, 1938; Milstein and Brock, 1954) myocardial anoxia (Juvenelle et al., 1952; Blades and Pierpont, 1954) an injury current (Osborn, 1953) acidosis (Covino and Hegnauer, 1955) or even to the Ta segment of atrial repolarization (Cazzullo and Macchi, 1954; Siems et al., 1955). None of these explanations seems correct.

The deflection is inscribed too slowly to be an ordinary secondary $R$ wave $\left(R^{\prime}\right)$. Its appearance in præcordial leads to the left and right of the chest in man does not resemble the pattern of either right or left bundle-branch block and is not like any pattern of myocardial injury clinically encountered in man. Further, the epicardial electrogram from the cooled canine heart does not resemble the monophasic or semi-monophasic curves obtained from the epicardium over areas of ischæmic damage at normal temperature (Rakita et al., 1954) or from undamaged epicardium by the use of cooled metal electrodes (Hoff and Geddes, 1955). The J loop, by which it is represented in the vectorcardiogram, is unlike anything previously described (Emslie-Smith, 1958). During periods of nodal rhythm and atrial fibrillation the characteristic deflection is not altered, as it would be if it were related to atrial repolarization.

Osborn (1953) found the deflection to be minimal or absent in surface leads in animals in whom the arterial $\mathrm{pH}$ was kept constant by manipulation of respiration, but we found that it developed irrespective of the $\mathrm{pH}$ of arterial blood (Fig. 6). This discrepancy is possibly explained by the fact that multiple leads were always used by us. Since the deflection may be obvious in chest leads, but absent from limb leads (Fig. 6E, F) and since the heart's position may alter during cooling, routine monitoring by a single limb lead might well give fallacious results.

It has been shown (Burgen and Terroux, 1953; Coraboeuf and Weidman, 1954) that in the single mammalian myocardial fibre cooling slows both depolarization and repolarization but at different rates. This suggests that in the intact heart the overall relationship between depolarization and repolarization is altered in hypothermia. Such an alteration could change the total unbalanced electrical activity of the heart at the time when depolarization ends and repolarization begins-at " $\mathrm{J}$ ", in fact-thus causing the $\mathrm{J}$ loop of the vectorcardiogram and the $\mathrm{J}$ deflection of the scalarlead electrocardiogram.

Whatever the cause of the $\mathbf{J}$ deflection it is not, as has been thought, something that occurs only 
in special adverse circumstances such as acidosis, myocardial injury or a sudden alteration in excitability. If carefully sought with suitable leads it is invariably found in hypothermia. It is therefore not surprising that when ventricular fibrillation occurs in hypothermia it usually does so after the appearance of the $\mathrm{J}$ deflection. This seems to be the only association between the two phenomena. The deflection is therefore valueless as a warning of ventricular fibrillation.

\section{SUMMARY}

The electrocardiogram has been studied by multiple surface leads during the production of preoperative hypothermia by skin-cooling in 10 anæsthetized patients, 8 of whom had no heart disease.

In all cases the heart rate slowed with falling temperature, and P-R and QTc increased. An extra, slowly-inscribed deflection ( $\mathrm{J}$ deflection) appeared in the early part of the S-T segment in some leads from all patients, though differing in magnitude and in the temperature at which it appeared. It was biggest and directed upward in leads related to the left ventricle. It grew in size as temperature fell. It was most conspicuous in the thinnest patients. When it became very high the $\mathrm{T}$ wave became inverted. It disappeared on rewarming.

Atrial fibrillation appeared in 6 patients at a mean temperature of $28.9^{\circ} \mathrm{C}$. (s.d. 1.17). Ventricular fibrillation did not occur. Neither in time of onset nor in severity did the changes in the electrocardiogram bear any relation to the onset of atrial fibrillation.

The effect of hypothermia on the S-T segment was studied in 55 experiments in dogs. Direct epicardial and intracavitary electrograms were recorded. These showed two basic patterns of change which were reflected, alone or in combination, by surface leads. The pattern obtained from most of the ventricular epicardium at low temperature resembled that recorded by left præcodial leads from the patients who showed the most severe changes.

No correlation was found between the time of onset or the severity of the changes and the onset of ventricular fibrillation. The characteristic deflection appeared irrespective of rhythm or the $\mathrm{pH}$ of arterial blood. Whatever its cause, the $\mathrm{J}$ deflection is invariably found in hypothermia, if sought with suitable leads. It is valueless as a warning of ventricular fibrillation.

We should like to thank Mr. K. C. Bradley, Mr. C. J. Officer Brown, Dr. R. H. Orton, and Dr. T. E. Lowe (Director of the Baker Medical Research Institute and Clinical Research Unit, Alfred Hospital) for help and encouragement, Dr. C. C. Curtain for estimating the blood pH, and Professor I. G. W. Hill for his help in the preparation of the manuscript.

\section{REFERENCES}

Blades, B., and Pierpont, H. C. (1954). Ann. Surg., 140, 557.

Burgen, A. S. V., and Terroux, K. G. (1953). J. Physiol., 119, 139.

Cazzullo, C. L., and Macchi, V. (1954). Fol. cardiol., 13, 235.

Coraboeuf, E., and Weidmann, S. (1954). Helv. physiol. Acta, 12, 32

Covino, B. G., and Hegnauer, A. H. (1955). Amer. J. Physiol., 181, 553.

- and Williams, L. (1955). Amer. J. Physiol., 181, 362.

Emslie-Smith, D. (1956). Australasian Ann. Med., 5, 62.

- (1958). Brit. Heart J., 20, 175.

Fleming, P. R., and Muir, F. H. (1957). Brit. Heart J., 19, 59.

Gunton, R. W., Scott, J. W., Lougheed, W. M., Botterell, E. H. (1956). Amer. Heart J., $52,419$.

Grosse-Brockhoff, F., and Schoedel, W. (1943). Arch. Exper. Path. Pharmakol., 201, 417.

Haeger, K., Johansson, B., and Sjöström, B. (1957). Amer. Heart J., 53, 31.

Hegnauer, A. H., and Covino, B. G. (1956). Amer. J. Physiol., 186, 511.

Hoff, H. E., and Geddes, L. A. (1955). J. Appl. Physiol., 7, 416.

Juvenelle, A., Lind, J., Wegelius, C. (1952). Presse méd., 60, 973.

Lougheed, W. M., Sweet, W. H., White, J. C., Brewster, W. R. (1955). J. Neurosurgery, 12, 240.

Milstein, B. B., and Brock, R. (1954). Guy's Hosp. Rep., 103, 213.

Osborn, J. J. (1953). Amer. J. Physiol., 175, 389.

Rakita, L., Borduas, J. L., Rothman, S., Prinzmetal, M. (1954). Amer. Heart J., 48, 351.

Schütz, E., and Rothschuh, K. E. (1942). Ztschr. ges. exper. Med., 110, 143.

Siems, M. V., Horvath, S. M., Spurr, G. B., Hutt, B. K., January, L. E. (1955). Amer. J. Physiol., $181,325$.

Tomaszewski, W. (1938). Arch. Mal. Caur, 31, 525.

Villamil, A., Clavijo, J., Franco, R. J., Buzzi, R. M., Abelardi, V. (1955). Acta. Physiol. latino-americana, 5, 104.

- Franco, R. J., Clavijo, J., Zuvira, E. M. (1957). Amer. Heart J., 53, 365. 